\title{
REVIEW
}

\section{Effective management of patients with electrical storm - networking and VT unit as essential parts for a successful outcome}

\author{
Elena Ene', Karin Nentwich', Phillipp Halbfaß',2, Kai Sonne', Arthur Berkovitz', Thomas Deneke',3
}

\begin{abstract}
Ventricular tachycardias (VT) represents worldwide one of the leading causes of sudden cardiac death. The increasing number of implanted ICDs have reduced significantly the number of sudden cardiac deaths SCDs); however recurrent VTs episodes might lead to a rapid deterioration of patient's clinical status and systolic function. An early intervention after a successful patient stabilization in a dedicated VT unit is mandatory for the mid- and long term prognosis of the patient. Nevertheless, a tight collaboration between general hospitals and highly specialized centers in treatment of patients with electrical storm is essential for an efficient and successful outcome.
\end{abstract}

Keywords: electrical storm, VT unit, catheter ablation.

Rezumat: Tahicardiile ventriculare (TV) reprezintă la nivel mondial una dintre cauzele cele mai frecvente de moarte cardiacă subită. Creșterea numărului de implanturi de ICD a redus semnificativ numărul de MCS; totuși la pacienții cu ICD, episoadele recurente de TV pot duce la o deteriorare rapidă a statusului clinic precum și a funcției sistolice ventriculare. Terapia intervențională (i.e ablația de TV), după stabilizarea hemodinamică inițială într-o unitate dedicate, este mandatorie pentru un prognostic favorabil pe termen mediu și lung.

Nu în ultimul rând o strânsă colaborare între centrele înalt specializate în tratamentul pacienților cu furtună electrică și centrele primare pentru asigurarea unui tratament eficient.

Cuvinte cheie: furtună electrică, VT unit, ablație prin cateter.

\section{INTRODUCTION}

The increasing number of implanted ICDs have led worldwide to a tremendous reduction of SCDs due to malignant ventricular tachycardia. However recurrent VTs might lead to a rapid deterioration progression of underlying heart disease, reduction of systolic function due to the tachymyopathie component and also have a negative psychological impact which further reduces the patient clinical status.

Electrical storm is defined as a number of at least 3 sustained VTs or ventricular fibrillation (VFs) episodes in 24 hours which requires an immediate intervention for termination (cardioversion/ defibrillation or ICD intervention). The VT/VF episodes are separated by one or more sinus rhythm beats and appears in more than 7 days after the date of ICD implantation.

\footnotetext{
' Cardiology Clinic II with interventional electrophysiology, Heart Center Campus Bad Neustadt, Germany

${ }^{2}$ Philipps Universität Marburg, Germany

${ }^{3}$ Ruhr - Universität Bochum, Germany
}

Electrical storm - very often not an isolated event requiring highly qualified management Electrical storm is a standalone predictor of mid- and long term mortality in patients coronary artery disease and VT/VFs an indicated by a substudy of MADIT II' Nevertheless, the patients presenting with VT storm have higher PAAINESD score which is further associated with a high early and midterm mortality ${ }^{2}$.

In more than half of the patients presenting with ES a trigger could be identified and this one should be carefully primary treated. Table I summarizes the most common triggers of ES.

The management of patients with ES should be ideally undergone in a tertiary center, on a dedicated unit (i..e VT unit) with a preexisting strong collaboration between structural heart disease respectively heart failure specialist and electrophysiologists.

\section{Contact address:}

Elena Ene, MD

Von-Guttenberg Str. II

97616 Bad Neustadt an der Saale, Germany

E-mail: Elena.ene@campus-nes.de 


\begin{tabular}{|c|c|c|}
\hline Trigger & Incidence & Relevance \\
\hline Infection & NA & ++ \\
\hline Proarrhythmic medication & NA & ++ \\
\hline Electrolyte imbalance & $4 \%$ & $(+)$ \\
\hline Psychological/emotional stress & $4-10 \%$ & Unknown \\
\hline Myocardial ischemia & $5-20 \%$ & $\begin{array}{l}+++ \\
\text { (in polymorphic VT) }\end{array}$ \\
\hline Worsening or new onset HF & $9-25 \%$ & Unknown \\
\hline unknown & $35-87 \%$ & \\
\hline
\end{tabular}

According to our internal protocol developed after many years of experience in treating the patients with ES the initial patient's stabilization algorhythm can be divided in 4 complementary phases as shown in Figure I. The three essential steps focus on: I). rhythm stabilization; 2). heart failure management and 3). ICD programming. As shown before the recurrent VT episodes might lead to very rapid decline of ventricular systolic function which further triggers new VT episodes so that in the daily practice the first 2 steps mentioned before are routinely performed concomitantly. Rhythm stabilization and heart failure management requires an acute strategy but also a long term concept. Rhythm stabilization can be achieved in most of the cases after correct identification and treatment of ES trigger; furthermore if this fails, in order to prevent the consequences of a low cardiac output syndrome, the implantation of hemodynamical assist device (HAD, i.e ECMO or Impella) should be considered as a short temporary solution or a bridge to permanent left respectively right ventricular assisting device in patients with terminal heart failure. Depending on the initial clinical premises the HAD could be also used during the VT ablation procedure, mostly in the case of a recurrent hemodynamical unstable VT whose elimination failed after a conventional (i.e substrate based) ablation. In these cases, an appropriate HAD facilitate the activation map and targeted ablation.

Generally, the antiarrhythmic medication should be considered and used as a short term option for

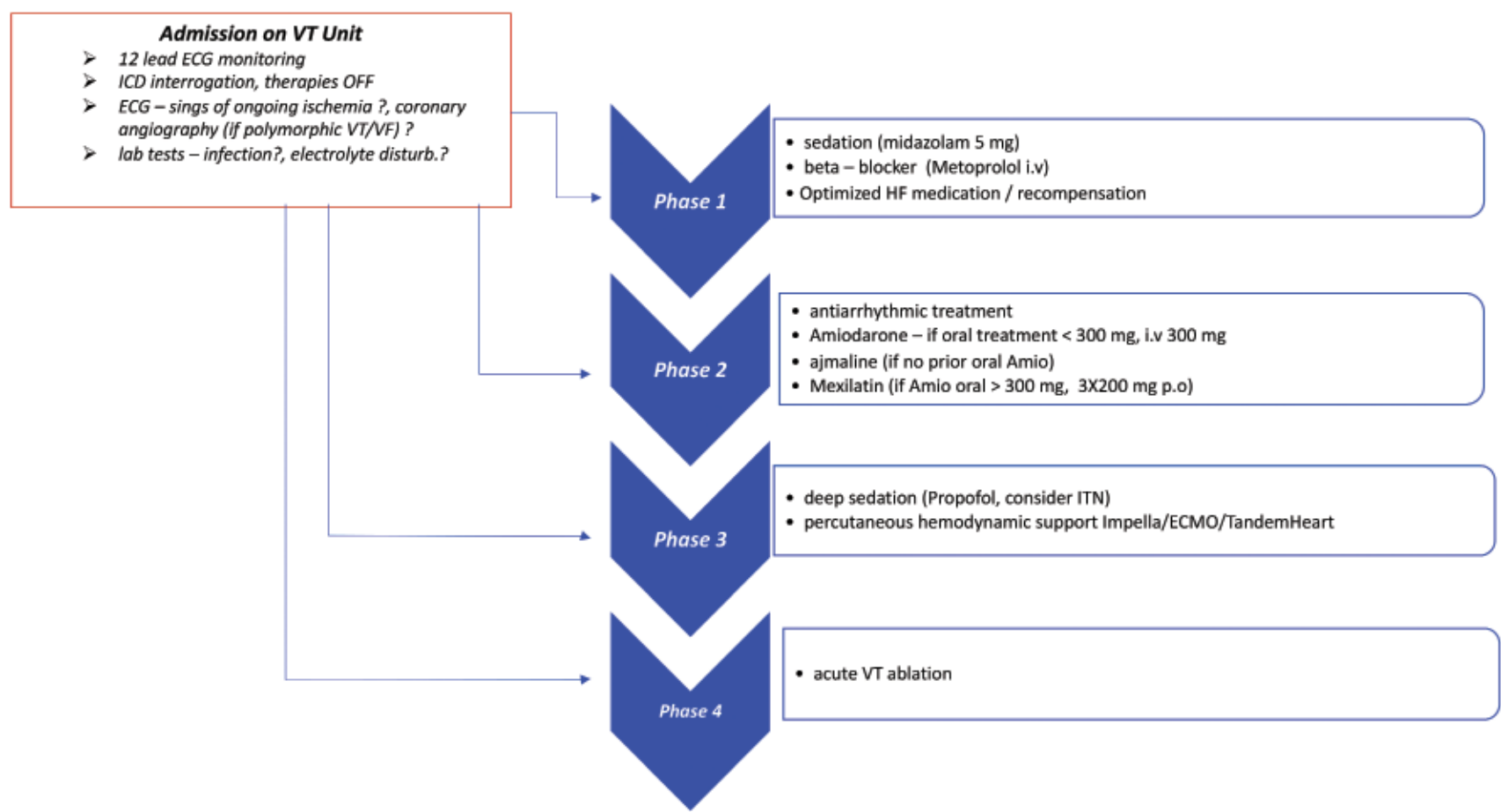

Figure I. Algorithm for acute management of patients admitted with electrical storm. 
rhythm stabilization. The only meaningful long therapy option in patient with ES is an early intervention i.e catheter ablation according to the class IB of the current ESC guidelines ${ }^{3}$. This aspect will be later discussed in a dedicated section. In very rare cases, special ablative therapy such as thoracal sympathectomy must be performed in order to achieve a long term rhythm stabilization.

An optimimal ICD programming should be focused on reduction of ICD shocks. This one can be achieved in acute phase by completely deactivation of ICD therapies and/or programming of long detection intervals, promoting repetitive ATPs instead of ICD shocks and ATP during charge. Nevertheless an CRT upgrade should be performed when indicated.

\section{Invasive treatment of electrical storm}

The superiority of catheter ablation compared to pharmacological therapy in treatment of patients with recurrent VTs was demonstrated in the VANISH study ${ }^{4}$. Through catheter ablation a significantly lower rate of ES recurrences compared to conservative therapy $(21 \%$ vs. $62 \%)$ can be achieved without a significant impact on mortality ${ }^{5}$. Of note, this difference was observed in patients with a LVEF $>25 \%$; this diference depending on LVEF could in explained by the higher rate of mortality due to terminal heart failure or noncardiac causes in patients with advanced heart failure (LVEF <25\%).
Based on the results of this studies the actual ESC guidelines recommends an early invasive strategy i.e catheter ablation in patients with ES (Class IB) ${ }^{3}$.

The long term prognosis after CA depends on the acute procedural success (no VT inducibility) respectively underlying structural heart disease. As expected a complete procedural success is associated with the best long term event free survival (till 92\% ES freedom and till $66 \%$ freedom from any $\mathrm{vt}$ ), whereas the patients who are still inducible at the of procedure despite extensive ablation have a higher ES recurrence rate ${ }^{6}$.

Patients with ischemic cardiomyopathy show a better long term VT recurrence free survival after a successful VT ablation comparing to patients with non-ischemic cardiomyopathy ${ }^{7,8}$. Nevertheless the VT ablation strategy also influences the long term recurrence rate, an extensive ablation (endo- and epicardial) being associated with a lower recurrence rate?

Concerning catheter ablation particularly in patients with ES two ablation concepts can be differentiated: an early ablation performed during initial hospitalization (i.e after successful rhythm stabilization to prevent recurrence of VT episodes) and acute ablation dedicated to rhythm stabilization when other noninvasive methods for rhythm stabilization (mainly pharmacological) have failed (Figure 2).

The acute ablation could be in some instances a real challenge because the hemodynamical status of the pa-

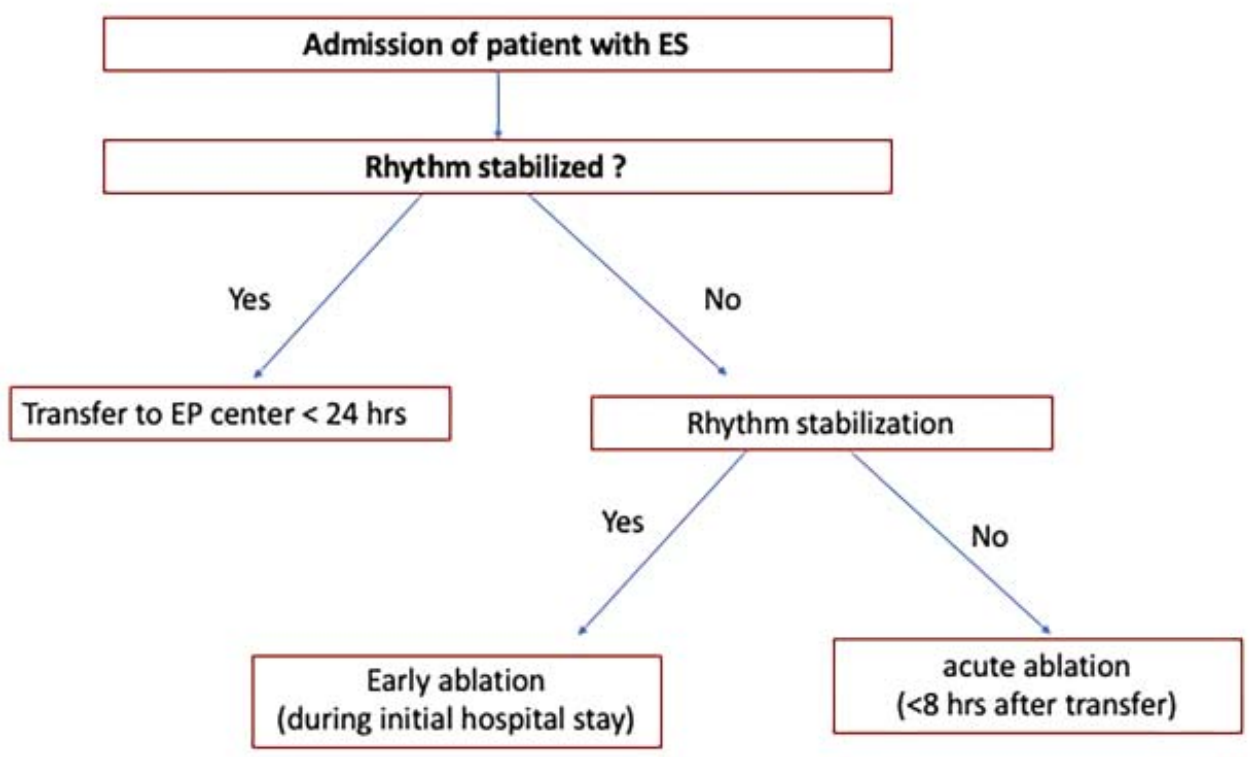

Figure 2. Organisation of electrical storm network. 
tient is very frail from the very beginning. In order to prevent the disastrous systemic consequences of a sustained low cardiac output syndrome in such cases a percutaneous hemodynamic assist device should be implanted before the procedure begin and maintained during the procedure. The choice between Impella, TandemHeart, ECMO should be done depending on the type of heart failure (predominantly left or right), procedure duration and postprocedural management plan (bridge to LVAD, bridge to transplant). A percutaneous hemodynamic support is also useful in case of redos, in patients in whom the ablation target remains still unclear despite already performed extensive VT ablation procedure when the clinical VT is still inducible (i.e. unclear mechanism of VT, target region localized in the interventricular septum, target region with failing substrate) Figure 3. It must be also considered that patients requiring percutaneous hemodynamically support are generally sicker, and no difference in terms of acute procedural success, VT recurrence and mortality was seen when compared to patients who received no percutaneous hemodynamically support during VT ablation ${ }^{10}$. A higher rate of complications (mostly bleeding and thromboembolic events) and higher radiation doses were registered.

In patients in whom an acute rhythm stabilization was achieved the scheduled early ablation should be performed using cardiac imaging guidance (Figure 4). As already demonstrated in many previous studies the best long term results (VT free survival) could be documented in patients in whom during the VT ablation real time cardiac imaging integration was used and in whom an extensive substrate modification was performed with elimination of all pathological potentials" ${ }^{\prime}$.

\section{Electrical storm management - Heart Center Bad Neustadt experience}

Since the foundation of VT unit and ES network in Heart Center Bad Neustadt in 2008 more that 350 patients with electrical storm have been here treated. The general trend showed an increasing number of patients with nonischemic cardiomyopathy who have been referred to our center for VT ablation. As one of the German national leading centers in epicardial VT ablation explains this trend as the patients with NIDCM very often have an extensive epicardial substrate as target of ablation. More than that an impressive decrease in number of in hospital death has been registered despite of highly complex and multimorbid patients. This trend reflects the tight collaboration between structural heart disease specialists, rhythmologists and cardiac surgeons as VT team. As a direct consequence the number of collaborating center have also increased from 8 in 2011 to 45 in 2019. Nevertheless, over the last 3 years the preprocedural per-
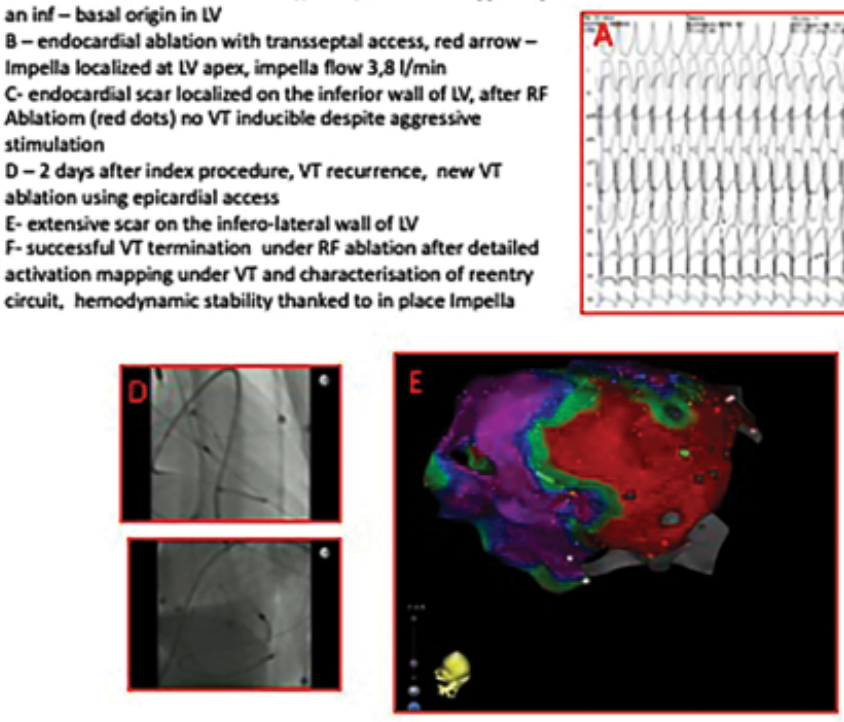
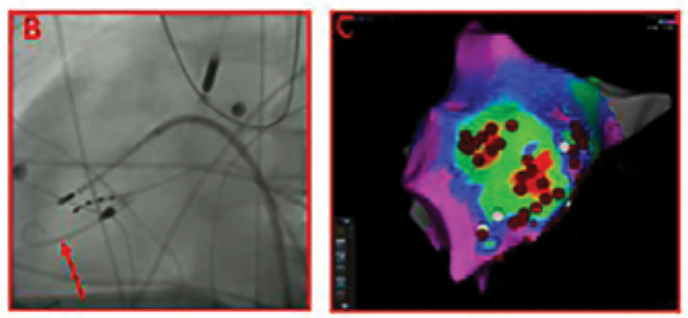
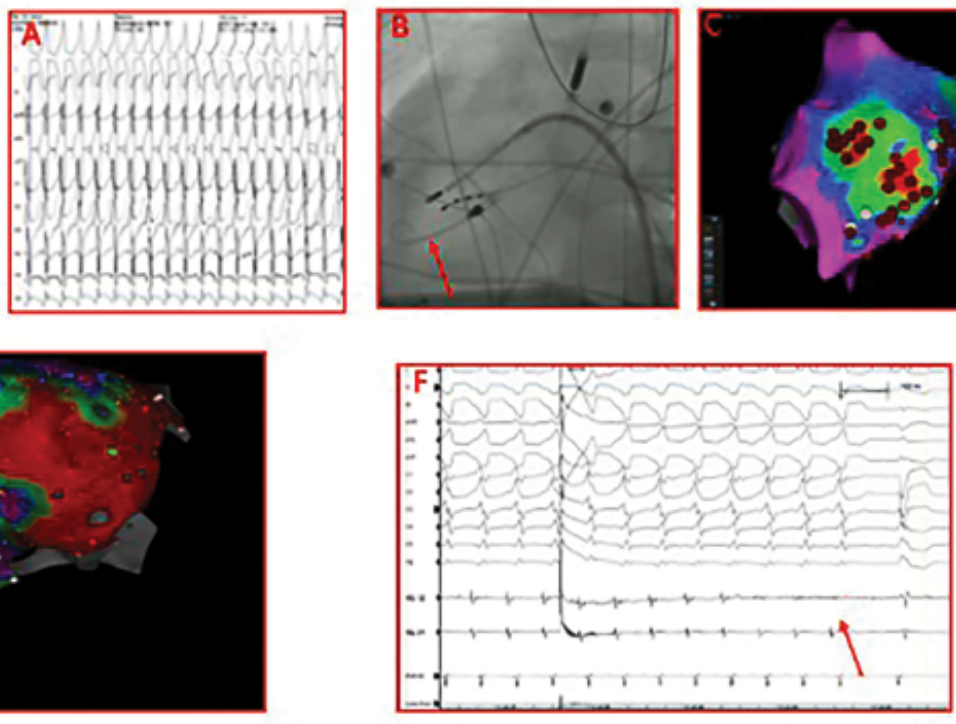

Figure 3. Case presentation: acute ablation for rhythm stabilization. 

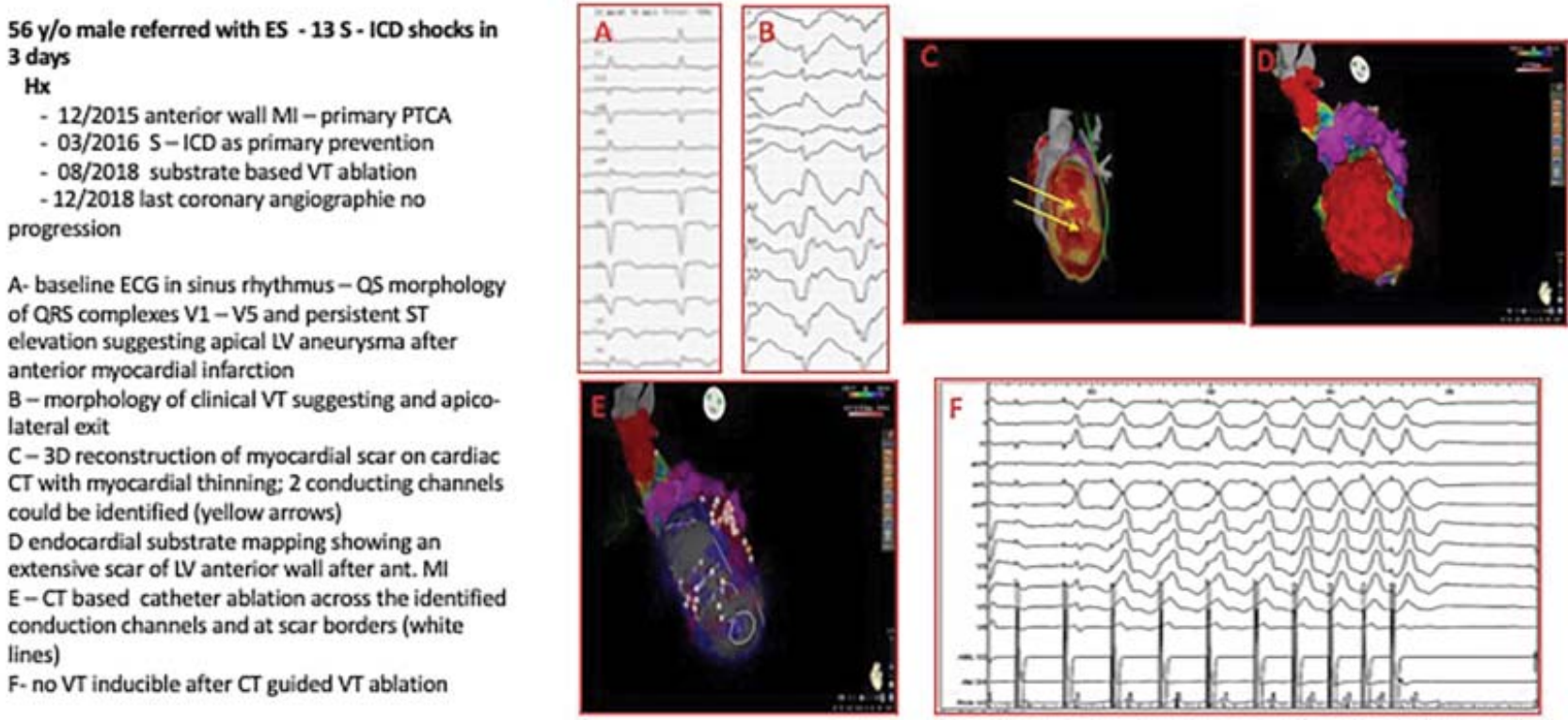

Figure 4. Case presentation: early ablation under guidance of cardiac imaging (cardio CT and myocardial thinning).

formed cardiac imaging in patients with ICM as part of multinational MUSIC VT project was a huge step towards a personalized, patient tailored VT ablation procedure and also helped in preprocedural defining of ablation targets.

Table 2 summarized the characteristics of patients admitted in 2019 on VT unit Heart Center Campus Bad Neustadt.

In conclusion the patient presenting with ES represents a challenge and an efficient initial management

\begin{tabular}{|c|c|}
\hline Total number & 35 \\
\hline $\begin{array}{l}\text { ICM } \\
\text { NIDCM }\end{array}$ & $\begin{array}{l}20(57 \%) \\
13(43 \%)\end{array}$ \\
\hline Electrical storm & $17(48 \%)$ \\
\hline Mean LVEF & $30.9 \% \pm 12.1 \%$ \\
\hline Endocardial ablation only & $21(60 \%)$ \\
\hline Epicardial ablation only & $5(14 \%)$ \\
\hline Combined approach (endo-/epi) & $5(14 \%)$ \\
\hline CPR before admission due to VT & $9(25 \%)$ \\
\hline Redo VT ablation & $21(60 \%)$ \\
\hline Procedure duration (min) & $146.13 \pm 48.8$ \\
\hline VT inducible before ablation & $24(68 \%)$ \\
\hline VT inducible after ablation & $10(28 \%)$ \\
\hline Cardiac imaging integration during VT ablation & $9(25 \%)$ \\
\hline Mean hospitalization duration on VT unit (days) & $12 \pm 5.8$ \\
\hline VT recurrence at 6 months & $4(11 \%)$ \\
\hline In hospital death & $\mathrm{I}(2 \%)$ \\
\hline
\end{tabular}

should be performed on a specialized dedicated VT unit where a strong collaboration between structural heart disease specialists and cardiac rhythmologists already exists. In many cases the ES is not an isolated rhythmological event and the triggers should be searched and primary treated.

For an effective and rapid rhythm stabilization standardized algohythms are necessary and strong collaboration between centers facilitate the optimization of patient's care and outcome.

Catheter ablation is an important part of the treatment strategy in ES patients and decreases recurrences but is challenging.

Conflict of interest: none declared.

\section{References}

I. Sesselberg H., Moss A., McNitt S., Zareba W., Daubert J.,Andrews M., Hall J., McClinitic B., Huang D., MADIT-II Research Group Ventricular arrhythmia storms in postinfarction patients with implantable defibrillators for primary prevention indications: a MADIT-II substudy. s.l.: Heart Rhythm, 2007, Vols. 4(I I):I395-402.

2. Santangeli P., Rame J.E., Birati E., Marchlinski F.Management of Ventricular Arrhythmias in Patients With Advanced Heart Failure. 14, s.l.: JACC, 2017, Vol. 69.

3. Silvia G Priori, Carina Blomström-Lundqvist, Andrea Mazzanti, Nico Blom, Martin Borggrefe, John Camm, Perry Mark Elliott, Donna Fitzsimons, Robert Hatala, Gerhard Hindricks, Paulus Kirchhof, Keld Kjeldsen, Karl-Heinz Kuck, Antonio Hernandez-Madrid, Nikola.20I5 ESC Guidelines for the management of patients with ventricular arrhythmias and the prevention of sudden cardiac death: The Task Force for the Management of Patients with Ventricular Arrhythmias and the Prevention of Sudden Cardiac Death of the Europe. 
36(4I):2793 - 2867, s.l.: Eur Heart J., 2015.

4. Sapp et al. Ventricular Tachycardia Ablation versus Escalation of Antiarrhythmic Drugs. N Engl J Med, 20I6, Vol. 375(2):I I I-2I, s.l...

5. Izquierdo et al.Ablation or conservative management of electrical storm due to monomorphic ventricular tachycardia: differences in outcome. Europace, 20I2, (I2):I734-9, s.l. :Vol. I4.

6. Carbucicchio et al. (Catheter ablation for the treatment of electrical storm in patients with implantable cardioverter-defibrillators: shortand long-term outcomes in a prospective single-center study. Circulation, 2008, Vol. I I74):462 - 9, s.l.

7. Muser D. et al. Long-Term Outcomes of Catheter Ablation of Electrical Storm in Nonischemic Dilated Cardiomyopathy Compared With Ischemic Cardiomyopathy. JACC Clin Electrophysiol., 2017, Vol. 3(7):767 - 778
8. Vergara et al. Successful ventricular tachycardia ablation in patients with electrical storm reduces recurrences and improves survival. Heart Rhythm, 2018, Vol. I5(I):48-55, s.l. :

9. Di Biase L. et al. Endo-epicardial homogenization of the scar versus limited substrate ablation for the treatment of electrical storms in patients with ischemic cardiomyopathy., J Am Coll Cardiol., 2012, Vol. 60(2): |32-4|.

10. Turagam et al. Percutaneous ventricular assist device in ventricular tachycardia ablation: a systematic review and meta-analysis. Interv Card Electrophysiol., 2019, Vol. 55(2): 197 - 205, s.l.: J.

II. Yamashita et al. Impact of New Technologies and Approaches for Post-Myocardial Infarction Ventricular Tachycardia Ablation During Long-Term Follow-Up. Circ Arrhythm Electrophysiol., 2016, Vol. 9(7). 